\title{
5-Episinuleptolide Decreases the Expression of the Extracellular Matrix in Early Biofilm Formation of Multi-Drug Resistant Acinetobacter baumannii
}

\author{
Sung-Pin Tseng ${ }^{1,2, *}$, Wei-Chun Hung ${ }^{3,+}$, Chiung-Yao Huang ${ }^{2,+}$, Yin-Shiou Lin ${ }^{1}$, Min-Yu Chan ${ }^{1}$, \\ Po-Liang $\mathrm{Lu}^{4,5,6}$, Lin Lin ${ }^{7}$ and Jyh-Horng Sheu ${ }^{2,8,9,10, *}$ \\ 1 Department of Medical Laboratory Science and Biotechnology, College of Health Sciences, \\ Kaohsiung Medical University, Kaohsiung 807, Taiwan; cookiecandy760428@hotmail.com (Y.-S.L.); \\ min116min@yahoo.com.tw (M.-Y.C.) \\ 2 Department of Marine Biotechnology and Resources, National Sun Yat-sen University, Kaohsiung 804, \\ Taiwan; huangcy@mail.nsysu.edu.tw \\ 3 Department of Microbiology and Immunology, Kaohsiung Medical University, Kaohsiung 807, Taiwan; \\ wchung@kmu.edu.tw \\ 4 Department of Laboratory Medicine, Kaohsiung Medical University Hospital, Kaohsiung 807, Taiwan; \\ d830166@cc.kmu.edu.tw \\ 5 College of Medicine, Kaohsiung Medical University, Kaohsiung 807, Taiwan \\ 6 Department of Internal Medicine, Kaohsiung Medical University Hospital, Kaohsiung 807, Taiwan \\ 7 Department of Culinary Art, I-Shou University, Kaohsiung 840, Taiwan; chang1025@msn.com \\ 8 Department of Medical Research, China Medical University Hospital, China Medical University, \\ Taichung 404, Taiwan \\ 9 Asia Pacific Ocean Research Center, National Sun Yat-sen University, Kaohsiung 804, Taiwan \\ 10 Frontier Center for Ocean Science and Technology, National Sun Yat-sen University, Kaohsiung 804, Taiwan \\ * Correspondence: tsengsp@kmu.edu.tw (S.-P.T.); sheu@mail.nsysu.edu.tw (J.-H.S.); \\ Tel.: +886-7-3121101 (ext. 2353) (S.-P.T.); +886-7-5252000 (ext. 5030) (J.-H.S.) \\ + These authors contributed equally to this work.
}

Academic Editor: Anake Kijjoa

Received: 24 February 2016; Accepted: 22 July 2016; Published: 29 July 2016

\begin{abstract}
Nosocomial infections and increasing multi-drug resistance caused by Acinetobacter baumannii have been recognized as emerging problems worldwide. Moreover, A. baumannii is able to colonize various abiotic materials and medical devices, making it difficult to eradicate and leading to ventilator-associated pneumonia, and bacteremia. Development of novel molecules that inhibit bacterial biofilm formation may be an alternative prophylactic option for the treatment of biofilm-associated A. baumannii infections. Marine environments, which are unlike their terrestrial counterparts, harbor an abundant biodiversity of marine organisms that produce novel bioactive natural products with pharmaceutical potential. In this study, we identified 5-episinuleptolide, which was isolated from Sinularia leptoclados, as an inhibitor of biofilm formation in ATCC 19606 and three multi-drug resistant A. baumannii strains. In addition, the anti-biofilm activities of 5-episinuleptolide were observed for Gram-negative bacteria but not for Gram-positive bacteria, indicating that the inhibition mechanism of 5-episinuleptolide is effective against only Gram-negative bacteria. The mechanism of biofilm inhibition was demonstrated to correlate to decreased gene expression from the $p g a A B C D$ locus, which encodes the extracellular polysaccharide poly- $\beta$-(1,6)- $N$-acetylglucosamine (PNAG). Scanning electron microscopy (SEM) indicated that extracellular matrix of the biofilm was dramatically decreased by treatment with 5-episinuleptolide. Our study showed potentially synergistic activity of combination therapy with 5-episinuleptolide and levofloxacin against biofilm formation and biofilm cells. These data indicate that inhibition of biofilm formation via 5-episinuleptolide may represent another prophylactic option for solving the persistent problem of biofilm-associated A. baumannii infections.
\end{abstract}


Keywords: 5-Episinuleptolide; biofilm; multi-drug resistant $A$. baumannii

\section{Introduction}

Acinetobacter baumannii is a Gram-negative, non-fermenting bacillus that is primarily found in healthcare and hospital environments. Recently, nosocomial infections and multi-drug resistance have been identified as emerging global problems [1,2]. Multi-drug resistant and pan-resistant $A$. baumannii strains have expanded globally and have now been found throughout the world, and only a few antibiotics can effectively treat these bacterial infections [3]. The major concern with A. baumannii is its ability to colonize various abiotic materials and medical devices, as it can cause ventilator-associated pneumonia, bacteremia, and wound infections [4,5]. Biofilm formation aids bacterial survival in strict nutrient-limiting environments and decreases their susceptibility to antibiotics [1,6]. In A. baumannii, the $p g a A B C D$ locus encodes proteins required for the production of poly- $\beta-(1,6)-N$-acetylglucosamine (PNAG), an extracellular polysaccharide that is important for biofilm formation [7]. PNAG has been shown to be a major component of Staphylococcus aureus, S. epidermidis and Escherichia coli biofilms [8-10]. Furthermore, PNAG is an important virulence factor that protects bacteria from the host innate immune system [11]. The bla $a_{\mathrm{PER}-1}$ gene is an extended-spectrum $\beta$-lactamase-encoding gene that is associated with cell adhesiveness and biofilm formation in A. baumannii [12]. Biofilm-associated protein (Bap) also plays an important role in colonization and biofilm formation [13-15]. The Bap protein is characterized as a large protein containing multiple tandem repeats that is able to anchor onto a cellular surface. Recent studies have found that the Bap protein is involved in initial adherence, biofilm maturation and maintenance in A. baumannii [16,17].

Biofilm formation serves as a barrier that significantly decreases the penetration of drugs into the biofilm, and bacteria within the biofilm are thus exposed to sub-lethal concentrations of antibiotics [18]. Sub-lethal concentrations of antibiotics increase mutation rates and the likelihood of plasmids and transposon transfer, thus selecting for resistant bacterial cells $[19,20]$. Thus, the development of anti-biofilm compounds could be an effective alternative strategy for treating biofilm infections. PGG $(1,2,3,4,6$-penta-O-galloyl- $\beta$-D-glucopyranose) is an active antioxidant ingredient found in geraniums, which are commonly used in Chinese medicine to treat inflammation [21,22]. PGG decreased biofilm formation by inhibiting initial attachment and the synthesis of PNAG [23]. Pinkston et al. developed a monoclonal antibody that targets a major component of Enterococcus faecalis pili (EbpC) and found that it diminished biofilm formation [24]. Weng et al. reported a quorum sensing inhibitor (F5) derived from Pseudomonas spp. JM2 that interferes with the las system (quorum sensing system) and significantly inhibits biofilm formation in P. aeruginosa [25]. However, only one study reported that a small organic molecule (virstatin) inhibits pili biosynthesis to prevent biofilm formation by A. baumannii [26].

Marine natural products have demonstrated pharmaceutical potential, particularly for the development of anticancer [27], antiviral [28] and antibacterial drugs [29]. The soft corals of the Sinularia genus are well known for producing bioactive and structurally versatile natural compounds [30]. The norcembranoids sinuleptolide and 5-episinuleptolide (Figure 1) have been isolated from the Formosan soft corals Sinularia scabra [31], S. parva [32], and S. leptoclados [32]. Later, they were again isolated from the coral $S$. lochmodes and the absolute molecular structures of both isomers were established [33]. Both norcembranoids were shown to inhibit LPS-induced TNF- $\alpha$ and nitric oxide production in murine macrophage RAW 246.7 cells [34], and they also inhibited the growth of several cancer cell lines [31]. Previous studies have demonstrated that bacteria can survive in hostile conditions, such as nutrient limitation and the presence of antimicrobial compounds via biofilm formation [4-6]. Indeed, the efficacy of anti-biofilm drugs has not yet been established in clinical biofilm-associated infections. In this study, 5-episinuleptolide was tested for its ability to inhibit biofilm formation, and the mechanisms of biofilm inhibition were investigated in multi-drug resistant $A$. baumannii strains. 
Furthermore, we determined that 5-episinuleptolide, isolated from S. leptoclados, could diminish biofilm formation by multi-drug resistant A. baumannii.

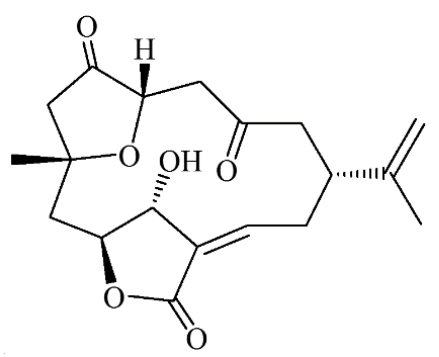

Figure 1. Chemical structure of 5-episinuleptolide.

\section{Results}

\subsection{Efficacy of 5-Episinuleptolide against A. baumannii Biofilm Formation Rather Than Eradication of Biofilm}

To test the activity of 5-episinuleptolide against $A$. baumannii biofilm formation and eradication of biofilm, the effect of bacterial growth was first tested with A. baumannii ATCC 19606. At 50 $\mu \mathrm{M}, 20 \mu \mathrm{M}$, and $5 \mu \mathrm{M}, 5$-episinuleptolide did not inhibit bacterial growth at $24 \mathrm{~h}$, a result that was confirmed by plate count methods (at $50 \mu \mathrm{M}, 9.1 \pm 0.7 \times 10^{8} \mathrm{CFU} / \mathrm{mL}$; at $20 \mu \mathrm{M}, 8.6 \pm 0.5 \times 10^{8} \mathrm{CFU} / \mathrm{mL}$; at $5 \mu \mathrm{M}$, $8.8 \pm 1.2 \times 10^{8} \mathrm{CFU} / \mathrm{mL}$ and at $\left.0 \mu \mathrm{M}, 9.0 \pm 1.1 \times 10^{8} \mathrm{CFU} / \mathrm{mL}\right)$. The activity of anti-biofilm growth increased with increasing concentrations of 5-episinuleptolide, which showed significant anti-biofilm activity at $50 \mu \mathrm{M}(49.38 \%$ at $24 \mathrm{~h} ; 45.21 \%$ at $48 \mathrm{~h})$ and $20 \mu \mathrm{M}(55.58 \%$ at $24 \mathrm{~h} ; 52.3 \%$ at $48 \mathrm{~h})(p<0.05)$ (Figure 2). The similar anti-biofilm activity at $24 \mathrm{~h}$ and $48 \mathrm{~h}$ indicated that 5-episinuleptolide could persist for $48 \mathrm{~h}$. The eradication ability of 5-episinuleptolide was tested with A. baumannii ATCC 19606, and it was found that no significant differences among different concentrations of 5-episinuleptolide (data not shown). These results indicate that 5-episinuleptolide inhibits biofilm growth rather than eradicating biofilm.

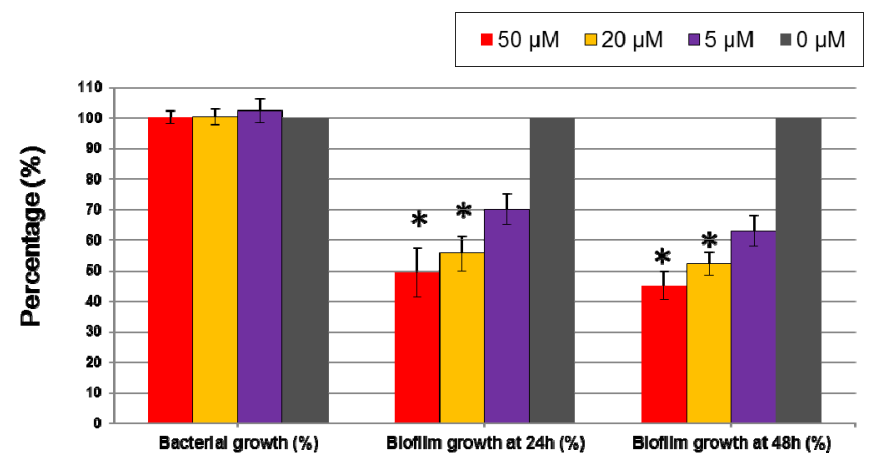

Figure 2. Effect of 5-episinuleptolide on biofilm formation of Acinetobacter baumannii ATCC 19606. Biofilm formation was determined by a microtiter plate assay with TSB medium supplemented with $1 \%$ glucose. An untreated control set as $100 \%$ in bacterial growth and biofilm growth. Experiments were performed in triplicate.

\subsection{Antimicrobial Susceptibility Testing of Multi-Drug Resistant A. baumannii Isolates}

The results of antimicrobial susceptibility testing, organized into nine categories, are presented in Table 1. Pseudomonas aeruginosa ATCC 27853 and E. coli ATCC 25922 were used as quality control strains for the antibiotics. Among three clinical isolates, A. baumannii 29115 and 68704 were resistant to six antibiotics but were susceptible to colistin (Table 1). A. baumannii D4 was resistant to eight antibiotics and was susceptible to only colistin. Infections with multi-drug resistant $A$. baumannii isolates are 
difficult to treat, as many of the currently used antibiotics are not effective against these isolates. If these isolates were to form biofilms, further reduced antibiotic susceptibility would represent a serious treatment problem.

Table 1. Antimicrobial susceptibilities of A. baumannii isolates.

\begin{tabular}{cccccc}
\hline \multirow{2}{*}{ Antibiotics $^{\text {a }}$} & \multicolumn{5}{c}{ A. baumannii Isolates } \\
\cline { 2 - 5 } & ATCC 19606 & BAA747 & $\mathbf{2 9 1 1 5}$ & $\mathbf{6 8 7 0 4}$ & D4 \\
\hline SXT & $>8 / 152(\mathrm{R})$ & $<1 / 19(\mathrm{~S})$ & $>8 / 152(\mathrm{R})$ & $>8 / 152(\mathrm{R})$ & $>8 / 152(\mathrm{R})$ \\
DOX & $<2(\mathrm{~S})$ & $<2(\mathrm{~S})$ & $64(\mathrm{R})$ & $64(\mathrm{R})$ & $64(\mathrm{R})$ \\
TIM & $128 / 2(\mathrm{R})$ & $16 / 2(\mathrm{~S})$ & $32 / 2(\mathrm{I})$ & $32 / 2(\mathrm{I})$ & $256 / 2(\mathrm{R})$ \\
CT & $<1(\mathrm{~S})$ & $<1(\mathrm{~S})$ & $<1(\mathrm{~S})$ & $<1(\mathrm{~S})$ & $<1(\mathrm{~S})$ \\
CAZ & $16(\mathrm{I})$ & $16(\mathrm{I})$ & $>128(\mathrm{R})$ & $>128(\mathrm{R})$ & $>128(\mathrm{R})$ \\
MEM & $<2(\mathrm{~S})$ & $<2(\mathrm{~S})$ & $32(\mathrm{R})$ & $64(\mathrm{R})$ & $>128(\mathrm{R})$ \\
GM & $32(\mathrm{R})$ & $<2(\mathrm{~S})$ & $>128(\mathrm{R})$ & $>128(\mathrm{R})$ & $>128(\mathrm{R})$ \\
LEV & $<1(\mathrm{~S})$ & $<1(\mathrm{~S})$ & $16(\mathrm{R})$ & $32(\mathrm{R})$ & $32(\mathrm{R})$ \\
TIC & $128(\mathrm{R})$ & $16(\mathrm{~S})$ & $32(\mathrm{I})$ & $32(\mathrm{I})$ & $128(\mathrm{R})$ \\
\hline
\end{tabular}

a SXT: Trimethoprim-sulfamethoxazole; DOX: Doxycycline; TIM: Ticarcillin-clavulanic acid; CT: Colistin;

CAZ: Ceftazidime; MEM: Meropenem; GM: Gentamicin; LEV: Levofloxacin; TIC: Ticarcillin.

2.3. Inhibition of Biofilm Formation by 5-Episinuleptolide in Multi-Drug Resistant A. baumannii Clinical Isolates and Reference Strains

To test the inhibitory activity of 5-episinuleptolide against biofilm formation by multi-drug resistant A. baumannii clinical isolates, A. baumannii 29115, 68704 and D4 were employed. The ratios of inhibition for these isolates were similar to that for A. baumannii ATCC 19606 (Table 2). Biofilm growth was 59.9\% (A. baumannii 29115), 45.83\% (A. baumannii 68704), and 43.9\% (A. baumannii D4) at $50 \mu \mathrm{M}$, and $61.07 \%$ (A. baumannii 29115), 87.13\% (A. baumannii 68704), and 60.23\% (A. baumannii D4) at $20 \mu \mathrm{M}$, respectively.

Table 2. Inhibition of biofilm formation by 5-episinuleptolide in multi-drugs resistant $A$. baumannii clinical isolates and four reference strains.

\begin{tabular}{|c|c|c|c|c|c|c|}
\hline \multirow{2}{*}{ Strain } & \multicolumn{3}{|c|}{ Bacterial Growth (\%) } & \multicolumn{3}{|c|}{ Biofilm Growth (\%) } \\
\hline & $50 \mu \mathrm{M}$ & $20 \mu \mathrm{M}$ & $5 \mu \mathbf{M}$ & $50 \mu \mathrm{M}$ & $20 \mu \mathrm{M}$ & $5 \mu \mathbf{M}$ \\
\hline \multicolumn{7}{|l|}{ A. baumannii } \\
\hline ATCC 19606 & $100.2 \pm 2.1$ & $100.4 \pm 2.7$ & $102.4 \pm 4.1$ & $49.38 \pm 8.1$ * & $55.58 \pm 5.6^{*}$ & $70.02 \pm 5.0$ \\
\hline 29115 & $96.2 \pm 2.3$ & $100.3 \pm 4.4$ & $103.1 \pm 4.8$ & $59.90 \pm 6.1$ * & $61.07 \pm 4.2 *$ & $76.81 \pm 8.7$ \\
\hline 68704 & $105.8 \pm 7.2$ & $98.4 \pm 6.2$ & $103.9 \pm 4.9$ & $45.83 \pm 2.2 *$ & $87.13 \pm 5.4$ & $96.33 \pm 6.0$ \\
\hline D4 & $102.4 \pm 2.9$ & $98.6 \pm 2.3$ & $97.7 \pm 5.5$ & $43.90 \pm 3.8^{*}$ & $60.23 \pm 4.6^{*}$ & $78.75 \pm 6.7$ \\
\hline E. coli & & & & & & \\
\hline $\begin{array}{l}\text { ATCC } 25922 \\
\text { P. aeruginosa }\end{array}$ & $99.5 \pm 6.2$ & $98.5 \pm 3.7$ & $100.4 \pm 8.2$ & $45.48 \pm 7.7^{*}$ & $50.18 \pm 9.4^{*}$ & $82.33 \pm 7.1$ \\
\hline $\begin{array}{c}\text { ATCC } 27853 \\
\text { S. aureus }\end{array}$ & $100.5 \pm 7.6$ & $108.9 \pm 6.1$ & $102.8 \pm 5.7$ & $53.01 \pm 3.8$ * & $77.82 \pm 5.5$ & $95.48 \pm 9.2$ \\
\hline $\begin{array}{l}\text { ATCC } 29213 \\
\text { S. epidermidis }\end{array}$ & $103.3 \pm 9.3$ & $99.7 \pm 5.6$ & $105.3 \pm 9.2$ & $90.25 \pm 7.4$ & $99.57 \pm 6.8$ & $103.82 \pm 5.6$ \\
\hline RP62A & $99.7 \pm 9.5$ & $99.4 \pm 2.8$ & $98.7 \pm 7.4$ & $88.98 \pm 7.9$ & $113.06 \pm 10.1$ & $116.19 \pm 8.1$ \\
\hline
\end{tabular}

To investigate whether the inhibition of biofilm formation differed between Gram-negative and Gram-positive bacteria, four reference strains, including Gram-negative bacteria (E. coli ATCC 25922 and P. aeruginosa ATCC 33592) and Gram-positive bacteria (S. aureus ATCC 29213 and S. epidermidis RP62A) were tested. Anti-biofilm activities were observed with Gram-negative bacteria but not 
with Gram-positive bacteria (Table 2). These results indicated that the anti-biofilm activity of 5-episinuleptolide is active against Gram-negative bacteria but not against Gram-positive bacteria.

\subsection{Investigation of the Biofilm Inhibitory Mechanism of 5-Episinuleptolide}

Because Bap, PNAG, and quorum sensing are known to be important for biofilm formation $[35,36]$, these parameters were analyzed using an adhesion assay, SEM and quantitative RNA expression analysis. There were no significant differences in adherence between the untreated control and the 5-episinuleptolide treated cells (Figure 3).

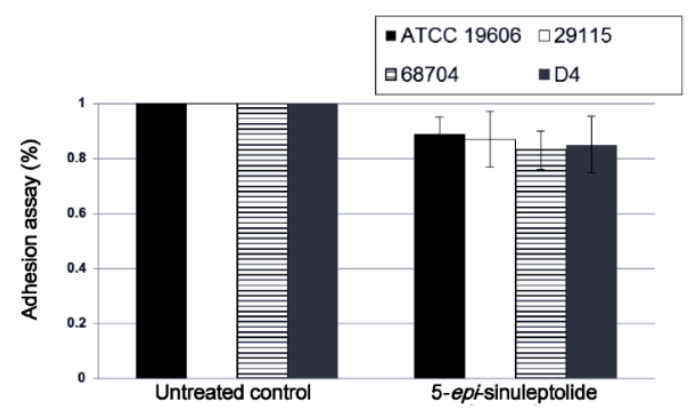

Figure 3. Effect of 5-episinuleptolide on bacterial adhesion. Bacterial strains were cultured in TSB $_{\text {gluc }} 1_{\%}$ broth with or without 5-episinuleptolide in 96-well microtiter plates at $37^{\circ} \mathrm{C}$ for $4 \mathrm{~h}$. Experiments were performed in triplicate.

Furthermore, quantitative RNA expression analysis of bap showed that bap expression was not altered by 5-episinuleptolide treatment (Figure 4a). These data indicate that Bap is not the target of 5 -episinuleptolide. The effect of the drug on the autoinducer synthase (AbaI) for quorum sensing was also analyzed by quantitative RNA expression. However, the expression of $a b a I$ was not altered by 5-episinuleptolide treatment, indicating that $\mathrm{AbaI}$ is not the target of 5-episinuleptolide (Figure $4 \mathrm{~b}$ ). SEM examination indicated that ATCC 19606 cells were completely embedded in extracellular polymeric substances in the untreated control (Figure 5a,b), while the amount of biofilm extracellular matrix was dramatically decreased by 5 -episinuleptolide treatment at $20 \mu \mathrm{M}$ (Figure 5c,d). Quantitative RNA analysis showed that treatment with 5-episinuleptolide significantly decreased the expression of $p g a A$ compared to the untreated control in all of the isolates $(p<0.05)$ (Figure $4 \mathrm{c})$. These results indicated that inhibition of PNAG synthesis by 5-episinuleptolide may decrease the expression of the extracellular matrix.

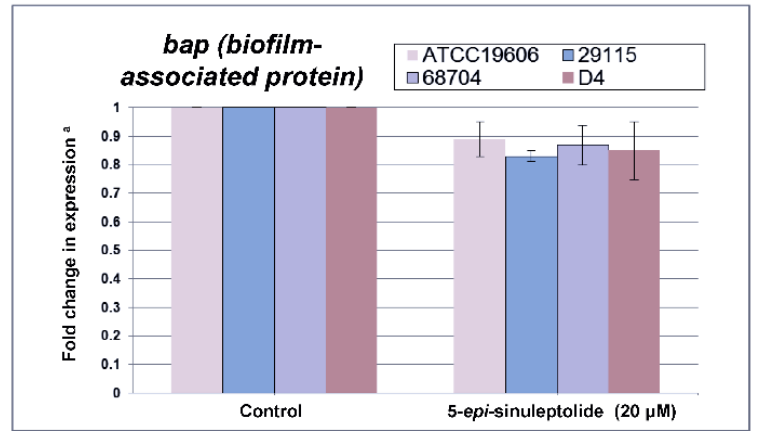

(a)

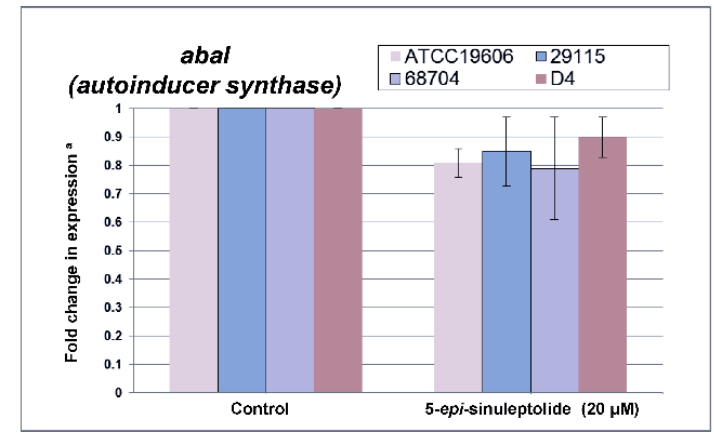

(b)

Figure 4. Cont. 


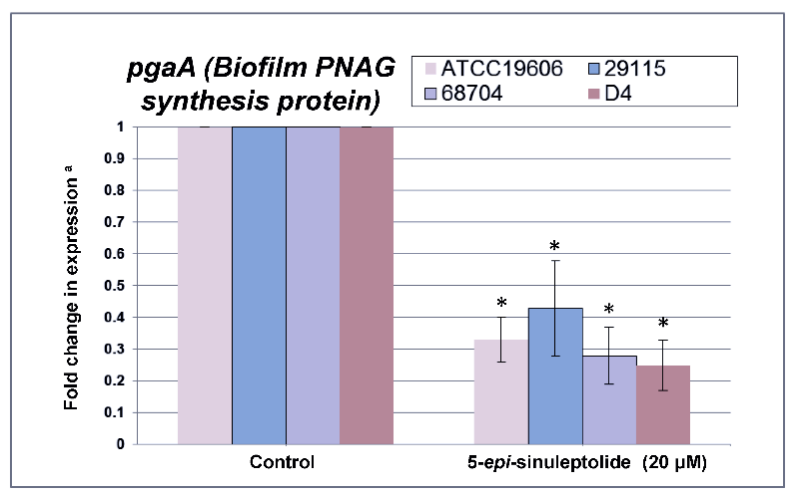

(c)

Figure 4. Quantitative RNA expression in A. baumannii strains treating with 5-episinuleptolide at 0 (control) and $20 \mu \mathrm{M}$ concentrations. (a) fold change in bap expression; (b) fold change in abaI expression; and (c) fold change in $p g a A$ expression. Experiments were performed in triplicate. ${ }^{*} p<0.05$ using the Mann-Whitney $U$ test.

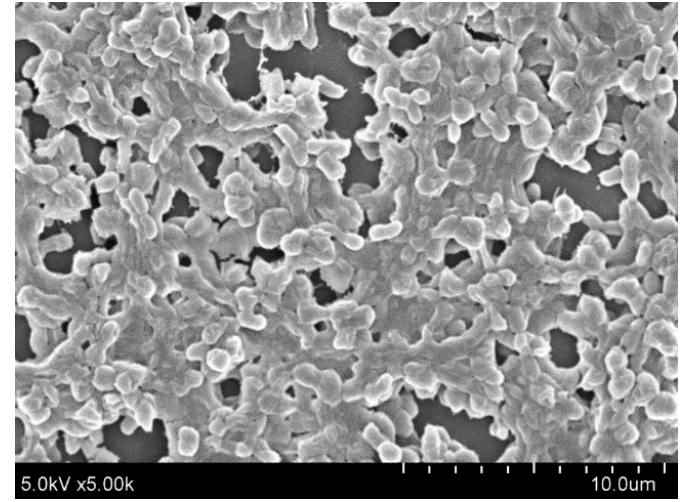

(a)

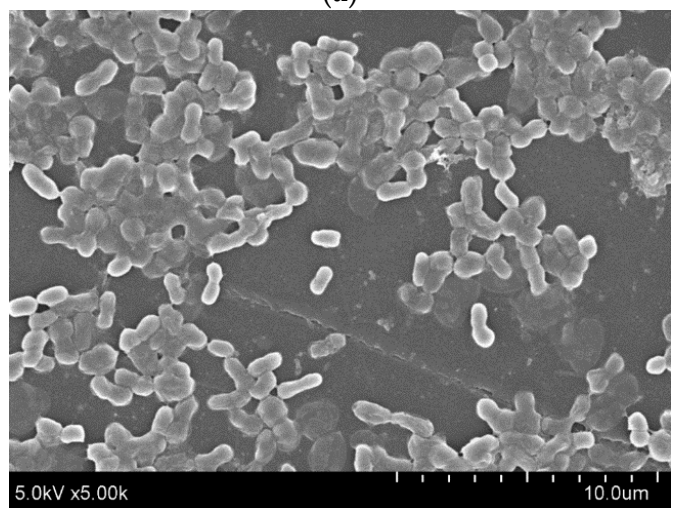

(c)

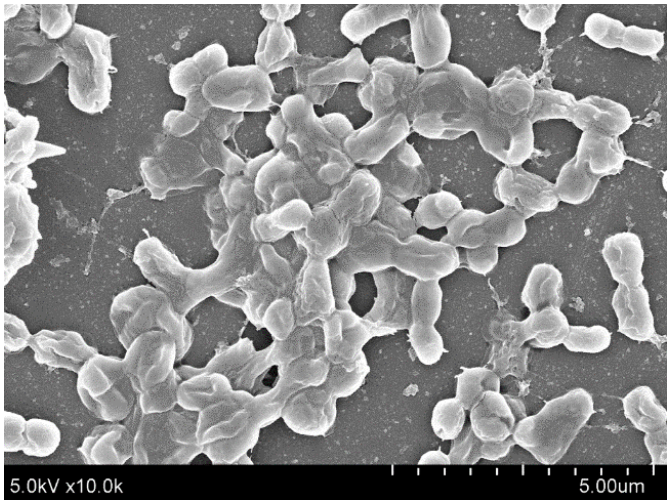

(b)

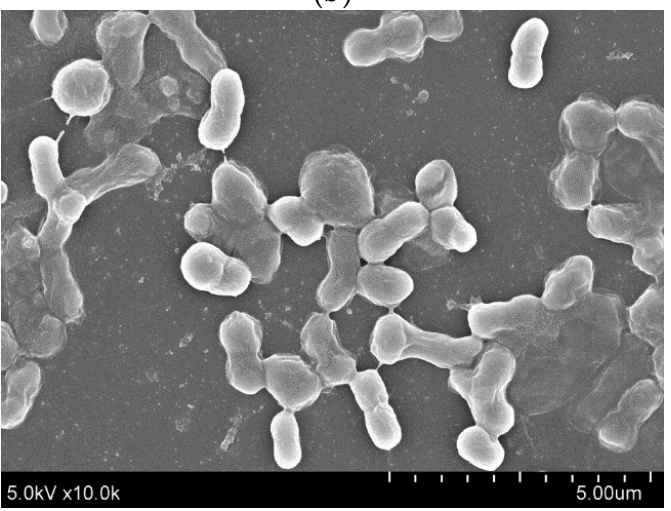

(d)

Figure 5. SEM images for biofilms of A. baumannii ATCC 19606 on polystyrene discs treating with 5-episinuleptolide at 0 and $20 \mu \mathrm{M}$ concentrations. (a) untreated control at 5000 $\times$ magnification; (b) untreated control at 10,000 × magnification; (c) treating with 5-episinuleptolide $(20 \mu \mathrm{M})$ at $5000 \times$ magnification; and (d) treating with 5-episinuleptolide $(20 \mu \mathrm{M})$ at 10,000 $\times$ magnification.

\subsection{Anti-Biofilm Efficacy of a Combination of 5-Episinuleptolide with Levofloxacin}

Levofloxacin, which is one of the outstanding 3rd-generation of quinolone antibiotics treating a number of bacterial infections, was selected to test the efficacy of combination therapy. To investigate combination therapy with 5-episinuleptolide and levofloxacin against biofilm formation, four A. baumannii strains were employed. The inhibitory ratios of 5-episinuleptolide in combination 
with $0.5 \times$ MIC (minimum inhibitory concentration) levofloxacin were significantly reduced when treated with 50 and $20 \mu \mathrm{M}$ 5-episinuleptolide $\left({ }^{*} p<0.05\right)$ (Table 3). Biofilm growth was $25.62 \%$ (A. baumannii ATCC 19606), 33.46\% (A. baumannii 29115), 27.47\% (A. baumannii 68704), and 26.35\% (A. baumannii D4) at $50 \mu \mathrm{M}$, and 31.83\% (A. baumannii ATCC 19606), 40.58\% (A. baumannii 29115), $47.46 \%$ (A. baumannii 68704), and 35.19\% (A. baumannii D4) at $20 \mu \mathrm{M}$, respectively.

Table 3. Inhibition of biofilm formation by 5-episinuleptolide in combination with $0.5 \times$ MIC (minimum inhibitory concentration) levofloxacin in four A. baumannii strains.

\begin{tabular}{|c|c|c|c|c|c|c|}
\hline \multirow{2}{*}{ Strain } & \multicolumn{3}{|c|}{ Biofilm Growth Without $0.5 \times$ MIC (\%) } & \multicolumn{3}{|c|}{ Biofilm Growth With $0.5 \times$ MIC (\%) } \\
\hline & $50 \mu \mathrm{M}$ & $20 \mu \mathrm{M}$ & $5 \mu \mathbf{M}$ & $50 \mu \mathrm{M}$ & $20 \mu \mathrm{M}$ & $5 \mu \mathbf{M}$ \\
\hline \multicolumn{7}{|l|}{ A. baumannii } \\
\hline ATCC 19606 & $49.38 \pm 8.1 *$ & $55.58 \pm 5.6^{*}$ & $70.02 \pm 5.0$ & $25.62 \pm 7.3 *$ & $31.83 \pm 4.4^{*}$ & $67.92 \pm 8.4$ \\
\hline 29115 & $59.90 \pm 6.1 *$ & $61.07 \pm 4.2 *$ & $76.81 \pm 8.7$ & $33.46 \pm 7.7 *$ & $40.58 \pm 8.7 *$ & $69.15 \pm 5.7$ \\
\hline 68704 & $45.83 \pm 2.2 *$ & $87.13 \pm 5.4$ & $96.33 \pm 6.0$ & $27.47 \pm 6.8 *$ & $47.46 \pm 3.6^{*}$ & $79.57 \pm 8.6$ \\
\hline D4 & $43.90 \pm 3.8 *$ & $60.23 \pm 4.6 *$ & $78.75 \pm 6.7$ & $26.35 \pm 8.4 *$ & $35.19 \pm 6.3 *$ & $71.73 \pm 7.7$ \\
\hline
\end{tabular}

To test combination therapy with 5-episinuleptolide and levofloxacin against biofilm cells, two bacterial strains (ATCC 19606 and D4) were employed. No significant differences were observed between the untreated controls and ATCC 19606 and D4 cells treated with $20 \mu \mathrm{M}$ 5-episinuleptolide (Figure 6a,b). When treated with $1 \times$ MIC levofloxacin, the biofilm cells of these strains also showed similar numbers between untreated controls and treatment with $20 \mu \mathrm{M}$ 5-episinuleptolide. In the presence of $4 \times \mathrm{MIC}$ levofloxacin, biofilm cells were significantly reduced when treated with $20 \mu \mathrm{M}$ 5-episinuleptolide $(p<0.05)$. These results indicated a potentially synergistic activity of 5-episinuleptolide and levofloxacin against biofilm formation and biofilm cells.

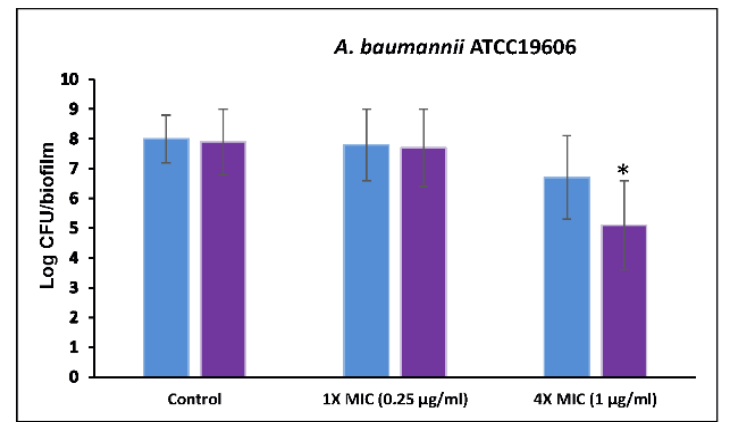

(a)

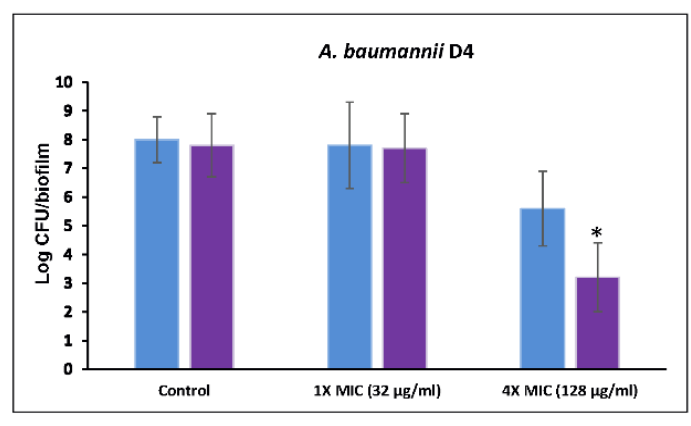

(b)

Figure 6. Efficacy of 5-episinuleptolide in combination with levofloxacin against biofilm cells. Untreated control (blue bars) and treating with 5-episinuleptolide $(20 \mu \mathrm{M})$ (purple bars) were exposed to levofloxacin in various concentration. (a) A. baumannii ATCC 19606; and (b) A. baumannii D4. Experiments were performed in triplicate. ${ }^{*} p<0.05$ using Mann-Whitney $U$ test.

\section{Discussion}

Antibiotic discovery is important for the treatment of infectious diseases. In the past century, different antibiotics have been discovered and successfully deployed against serious infections. However, the increasing prevalence of antibiotic-resistant bacteria has become a global health problem, i.e., bacteria are difficult to treat. Traditional antibiotic strategies that focus on killing bacteria or preventing bacterial growth have led to antibiotic resistance; however, inhibition of bacterial virulence and signaling pathways may represent alternative approaches for the treatment of bacterial infections [25,37,38]. 
Marine environments are unlike terrestrial environments, and the abundant biodiversity of marine organisms produce novel and bioactive natural products. In the past decade, more than 3000 newly identified marine-derived compounds have been reported having novel therapeutic uses [27]. Peach et al. found that auromomycin inhibits biofilm formation by Vibrio cholerae with an $\mathrm{IC}_{50}$ of $60.1 \mu \mathrm{M}$ [39]. Halogenated furanones produced by the marine red alga Delisea pulchra have been reported to inhibit the quorum sensing systems of Serratia liquefaciens, P. aeruginosa, and Bacillus subtilis [40-42]. This is the first study that reports the anti-biofilm activity of 5-episinuleptolide, a secondary metabolite isolated from Sinularia leptoclados, against a reference strain and multi-drug resistant isolates of A. baumannii (Table 2). 5-Episinuleptolide at $20 \mu \mathrm{M}$ concentration, which is negligibly harmful to nontransformed human skin fibroblast Hs68 cells ( $>95 \%$ cell survival) [43], could effectively inhibit biofilm formation. However, 5-episinuleptolide is an inhibitor of biofilm growth rather than a biofilm eradicator. These results suggest that applications of 5-episinuleptolide should be focused on biofilm prevention. Table 2 shows that anti-biofilm activities were observed for Gram-negative bacteria but not for Gram-positive bacteria. Most detailed analysis demonstrated that biofilm inhibition by 5-episinuleptolide involves decreased gene expression of the $p g a A B C D$ locus (Figure 4c). Although a quantitative RNA analysis showed the inhibition of PNAG synthesis by 5-episinuleptolide (Figure 4), quantitative PNAG protein was not detected in this study. Further experiments should be performed to confirm this finding.

Interestingly, 5-episinuleptolide did not inhibit biofilm formation in S. aureus ATCC 29213 and S. epidermidis RP62A (Table 2) even though they also produce PNAG. One reason for this difference may be due to PNAG being produced by a different gene locus in these species. A previous study revealed that icaADBC locus, which produced PNAG in S. epidermidis, is similar to $p g a A B C D$ locus in that they produce low protein [44]. The different protein sequences might explain different effects of 5-episinuleptolide on Gram-positive and Gram-negative bacteria. The absence of any significant difference in an adhesion assay indicated that initial step of biofilm formation (CsuA/BABCDE-mediated pili and Bap) was not targeted by 5-episinuleptolide (Figures 3 and $4 \mathrm{a}$ ). However, the autoinducer synthase (AbaI) of quorum sensing reportedly participates in biofilm maturation [45], the RNA expression of abaI was not altered by 5-episinuleptolide treatment, indicating that AbaI is not a target of 5-episinuleptolide (Figure 4b). Our previous study showed that tigecycline, imipenem-rifampicin and colistin-rifampicin would be effective for the prevention or reduction of biofilm formation in A. baumannii strains [46]. Our study revealed the potentially synergistic activity of 5-episinuleptolide and levofloxacin against biofilm formation (Table 3 and Figure $6 a, b$ ). A previous study revealed that 5 -episinuleptolide caused the inhibition of TNF- $\alpha$ and nitric oxide production in macrophages from several cancer cell lines, indicating an effect of the immune system [25]. Although the immune system may be affected by treatment with 5-episinuleptolide, possibly making it unsuitable for direct use against infections, this new lead compound could have potential for further discovery of anti-biofilm agents.

The global expansion of multi-drug resistant and pan-resistant $A$. baumannii strains has resulted in such strains being found throughout the world [3]. Only a few effective antibiotics can treat these bacterial infections, supporting the importance of biofilm inhibition as an alternative therapeutic option for their treatment. Chabane et al. found that a small organic molecule (virstatin) inhibits pili biosynthesis to prevent biofilm formation in A. baumannii [26]. Our finding revealed that 5-episinuleptolide could decrease gene expression from the $p g a A B C D$ locus, which is an important component of biofilm formation. Thus, the synergistic anti-biofilm effects of virstatin (pili biosynthesis) and 5-episinuleptolide (PNAG biosynthesis) might find potential use for inhibition of A. baumannii biofilm formation. 


\section{Materials and Methods}

\subsection{Marine Natural Products}

The compound of 5-episinuleptolide was isolated from Sinularia leptoclados, which was identified by Jyh-Horng Sheu, National Sun Yat-Sen University, Kaohsiung, Taiwan, as described previously [43]. 5-Episinuleptolide could induce apoptosis of human skin cancer cells [43]. The stock solution of 5-episinuleptolide was dissolved in dimethyl sulfoxide (DMSO) at a concentration of $100 \mathrm{mM}$. The stock solution was diluted to the desired final concentrations with growth medium immediately before use.

\subsection{Bacterial Isolates}

Two A. baumannii reference strains (ATCC 19606 and ATCC BAA747), E. coli ATCC 25922, P. aeruginosa ATCC33592, S. aureus ATCC 29213, S. epidermidis RP62A and three multi-drug resistance clinical isolates of $A$. baumannii, which were isolated from blood in Kaohsiung Medical University Chung-Ho Memorial Hospital in 2011, were analyzed in this study.

\subsection{Ethics Statement}

This study was approved by the Institutional Review Board (IRB) of Kaohsiung Medical University Chung-Ho Memorial Hospital, Kaohsiung, Taiwan (KMUHIRB-E(II)-20150159). The study subjects were bacterial isolates, and written consent was given by the patients was waived by the approving IRB.

\subsection{Antimicrobial Susceptibility Testing}

Antimicrobial susceptibility testing was performed by agar dilution according to the guidelines of the Clinical and Laboratory Standards Institute (CLSI) [35]. The MIC was defined as the lowest concentration of antibiotic that prevented bacterial growth after 20 to $24 \mathrm{~h}$ of incubation at $37^{\circ} \mathrm{C}$. The following antimicrobial agents were tested: ceftazidime, colistin, doxycycline, gentamicin, levofloxacin, meropenem, ticarcillin, ticarcillin-clavulanic acid, and trimethoprim-sulfamethoxazole.

\subsection{Measurement of Bacterial Growth}

Bacteria were cultured overnight at $37^{\circ} \mathrm{C}$ in TSB broth and adjusted to a McFarland 1.0 with $\mathrm{TSB}_{\text {gluc1\% }}$. Next, 1:50 dilutions were prepared with $\mathrm{TSB}_{\text {gluc1\% }}$ and transferred to 96-well flat-bottomed microtiter plates (Corning Incorporated, Corning, NY, USA). After $24 \mathrm{~h}$ of incubation at $37^{\circ} \mathrm{C}$, the bacterial density was determined at A600 using a microtiter plate reader (Molecular Devices, Sunnyvale, CA, USA) and confirmed by plate count methods.

\subsection{Adhesion and Biofilm Formation Assays}

Biofilm formation was assayed using the microtiter plate assay [47]. Briefly, bacteria were cultured

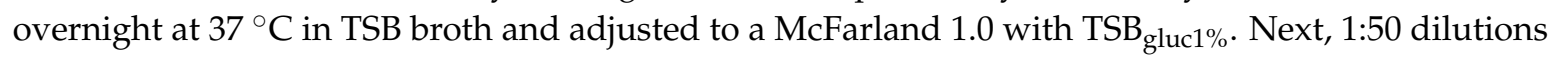
were prepared with $\mathrm{TSB}_{\text {gluc1\% }}$ and transferred to 96-well flat-bottomed microtiter plates (Corning Incorporated, Corning, NY, USA). Bacterial suspensions were incubated with 5-episinuleptolide at various concentrations $(0,5 \mu \mathrm{M}, 20 \mu \mathrm{M}$, and $50 \mu \mathrm{M})$. After $4 \mathrm{~h}$ (adhesion assay) or $24 \mathrm{~h}$ and $48 \mathrm{~h}$ (biofilm formation assay) of incubation at $37^{\circ} \mathrm{C}$, the wells were washed twice with water and then dried. Biofilms were stained with $0.6 \%$ crystal violet for $1 \mathrm{~min}$, washed twice with water to remove excess dye and then dried. The biofilm matrix was resuspended in $10 \%$ acetic acid, and the absorbance of the crystal violet was measured at $\mathrm{OD}_{570} \mathrm{~nm}$. S. epidermidis RP62A was used as a positive control, and experiments were performed in triplicate.

\subsection{Biofilm Eradication Assay}

To test the eradication ability of 5-episinuleptolide, the biofilm formation assay was modified to create a biofilm eradication assay. Briefly, bacteria were cultured overnight at $37^{\circ} \mathrm{C}$ in $\mathrm{TSB}$ broth 
and adjusted to a McFarland 1.0 with $\mathrm{TSB}_{\text {gluc1 }} \%$. Next, 1:50 dilutions were prepared with $\mathrm{TSB}_{\text {gluc }} \%$ and transferred to 96-well flat-bottomed microtiter plates (Corning Incorporated, Corning, NY, USA). After $24 \mathrm{~h}$ of biofilm growth at $37^{\circ} \mathrm{C}$, the wells were washed twice with water to remove non-adherent cells. Subsequently, the biofilm cells were treated with 5-episinuleptolide at various concentrations $(0,5 \mu \mathrm{M}, 20 \mu \mathrm{M}$, and $50 \mu \mathrm{M})$ for $24 \mathrm{~h}$ at $37^{\circ} \mathrm{C}$. The remaining biofilms were evaluated with crystal violet as biofilm formation assay.

\subsection{RNA Extraction and Synthesis of $c D N A$}

Total RNA was extracted from bacterial biofilm cells (untreated controls and cells treated with $20 \mu \mathrm{M}$ 5-episinuleptolide) using TRIzol reagent (Life Technologies, Carlsbad, CA, USA) according to the manufacturer's recommendations. Contaminating DNA was removed by DNase I (Life Technologies, Carlsbad, CA, USA) digestion for $45 \mathrm{~min}$ at $37^{\circ} \mathrm{C}$, followed by phenol-chloroform extraction, isopropanol precipitation, and resuspension of total RNA in nuclease-free water. Reverse transcription was performed with $5 \mu \mathrm{g}$ of RNA using random hexamers and M-MLV reverse transcriptase (Life Technologies, Carlsbad, CA, USA).

\subsection{Quantitative Reverse Transcription-PCR ( $q R T-P C R)$ for Biofilm-Related Genes}

PCR reactions were performed in 96-well plates in reaction buffer containing 1X FastStart Universal SYBR Green Master (Roche), $300 \mathrm{nM}$ primers and $2 \mu \mathrm{L}$ of cDNA. Reactions were conducted in an ABI7000 machine (Applied Biosystems, Carlsbad, CA, USA) following the manufacturer's protocol. Forward and reverse primers were developed using Primer-BLAST (http:/ /www.ncbi.nlm. nih.gov/tools/primer-blast/) and are listed in Table 4. Relative fold changes in the transcript levels of the indicated genes were normalized to the 16SrDNA gene (internal control) and calculated using the $2^{-\triangle \triangle C T}$ method.

Table 4. Primers used in this study.

\begin{tabular}{|c|c|c|c|c|}
\hline Target & Primer Name & Sequence $\left(5^{\prime}\right.$ to $\left.3^{\prime}\right)$ & Sizes (bp) & Reference \\
\hline \multirow{2}{*}{ 16SrDNA } & $16 S-F$ & TCCTCCAGTTTGTCACTGGC & \multirow{2}{*}{116} & \multirow{2}{*}{ This study } \\
\hline & $16 S-R$ & GTCAGCTCGTGTCGTGAGAT & & \\
\hline \multirow{2}{*}{ bap } & BAP-F & CCTTGGTAACCACAGAGGGA & \multirow[b]{2}{*}{114} & \multirow{2}{*}{ This study } \\
\hline & BAP-R & TGACTGCATTGGTACCCTCC & & \\
\hline \multirow{2}{*}{$p g a A$} & PGA-F & GCTGAAGCTCAAGATGTGGC & \multirow{2}{*}{91} & \multirow{2}{*}{ This study } \\
\hline & PGA-R & ATGCAACCCGTACCAACTGA & & \\
\hline \multirow{2}{*}{$a b a I$} & \multirow{2}{*}{$a b a I-F$ abaI-R } & GTACAGTCGACGTATTTGTTGAATATTTGGG & \multirow{2}{*}{382} & \multirow{2}{*}{ [44] } \\
\hline & & CGTACGTCTAGAGTAATGAGTTGTTTTGCGCC & & \\
\hline
\end{tabular}

\subsection{Analysis of Biofilm Formation by Scanning Electron Microscopy}

Biofilms were grown on polystyrene discs and were treated with 5-episinuleptolide at 0 or $20 \mu \mathrm{M}$. After $24 \mathrm{~h}$ of incubation, the discs were washed three times with PBS to remove planktonic cells and were prepared for SEM examination as previously described [16]. Samples were analyzed with an SU8010 scanning electron microscope (Hitachi, Tokyo, Japan).

\subsection{Anti-Biofilm Efficacy of 5-Episinuleptolide in Combination with Levofloxacin}

A combination of 5-episinuleptolide and levofloxacin was tested using a previously described method [48]. Briefly, biofilms were grown for $24 \mathrm{~h}$ in $\mathrm{TSB}_{\text {gluc } 1 \%}$ and treated with different concentrations of levofloxacin $(1 \times$ MIC and $4 \times$ MIC were tested) in combination with $20 \mu \mathrm{M}$ 5-episinuleptolide. Biofilms were grown on silicone discs (Q7-4735, Dow Corning, Midland, MI, USA) that were placed in the wells of a 24 -well microtiter plate. After $24 \mathrm{~h}$ of treatment, all discs were rinsed and transferred to $10 \mathrm{~mL}$ of $\mathrm{TSB}_{\text {gluc1\%. }}$. Bacterial cells were removed from the discs by vortexing (30 s) and sonication (30 s in an ultrasound sonicator DC400H, Yu Xin Instrument Co. Ltd., Tainan, Taiwan). Subsequently, the number of bacterial cells was optimized to approximately $10^{8}$ cells $/ \mathrm{mL}$, which were determined by plate count methods. Experiments were performed in triplicate. 


\subsection{Statistical Analysis}

The SPSS 15.0 program (SPSS, Inc., Chicago, IL, USA) was used for statistical analysis. A nonparametric test (the Mann-Whitney $U$ test) was used to examine the difference in biofilm formation between the untreated control group and the 5-episinuleptolide treated group. A $p<0.05$ threshold was considered significant for this analysis.

\section{Conclusions}

The natural compound 5-episinuleptolide, isolated from S. leptoclados, could diminish biofilm formation in ATCC 19606 and three multi-drug resistant A. baumannii strains. The mechanism of biofilm inhibition was attributed to decreased gene expression of the $p g a A B C D$ locus, whose products produce the extracellular polysaccharide poly- $\beta-(1,6)-N$-acetylglucosamine (PNAG). The use of 5-episinuleptolide may represent an alternative prophylactic option for solving the persistent problem of biofilm-associated A. baumannii infections.

Acknowledgments: This work was supported by grants from the National Sun Yat-sen University-Kaohsiung Medical University (NSYSU-KMU) Joint Research Project (NSYSUKMU104-I011 and 105-I003), Kaohsiung Medical University Research Foundation (KMU-M105014), and the Ministry of Science and Technology of Taiwan (MOST 104-2320-B-110-001-MY2).

Author Contributions: Conceived and designed the experiments: S.-P.T. and J.-H.S. Performed the experiments: W.-C.H., W.-C.T., Y.-S.L., and C.-Y.H. Analyzed the data: L.L. Contributed reagents/materials/analysis tools: P.-L.L. Contributed to the writing of the manuscript: S.-P.T. and J.-H.S.

Conflicts of Interest: The authors declare no conflict of interest.

\section{References}

1. Dijkshoorn, L.; Nemec, A.; Seifert, H. An increasing threat in hospitals: Multidrug-resistant Acinetobacter baumannii. Nat. Rev. Microbiol. 2007, 5, 939-951. [CrossRef] [PubMed]

2. Munoz-Price, L.S.; Arheart, K.; Nordmann, P.; Boulanger, A.E.; Cleary, T.; Alvarez, R.; Pizano, L.; Namias, N.; Kett, D.H.; Poirel, L. Eighteen years of experience with Acinetobacter baumannii in a tertiary care hospital. Crit. Care Med. 2013, 41, 2733-2742. [CrossRef] [PubMed]

3. Karageorgopoulos, D.E.; Falagas, M.E. Current control and treatment of multidrug-resistant Acinetobacter baumannii infections. Lancet Infect. Dis. 2008, 8, 751-762. [CrossRef]

4. Peleg, A.Y.; Seifert, H.; Paterson, D.L. Acinetobacter baumannii: Emergence of a successful pathogen. Clin. Microbiol. Rev. 2008, 21, 538-582. [CrossRef] [PubMed]

5. Sheppard, F.R.; Keiser, P.; Craft, D.W.; Gage, F.; Robson, M.; Brown, T.S.; Petersen, K.; Sincock, S.; Kasper, M.; Hawksworth, J.; et al. The majority of us combat casualty soft-tissue wounds are not infected or colonized upon arrival or during treatment at a continental us military medical facility. Am. J. Surg. 2010, 200, 489-495. [CrossRef] [PubMed]

6. De la Fuente-Nunez, C.; Reffuveille, F.; Fernandez, L.; Hancock, R.E. Bacterial biofilm development as a multicellular adaptation: Antibiotic resistance and new therapeutic strategies. Curr. Opin. Microbiol. 2013, 16, 580-589. [CrossRef] [PubMed]

7. Choi, A.H.; Slamti, L.; Avci, F.Y.; Pier, G.B.; Maira-Litran, T. The $p g a A B C D$ locus of Acinetobacter baumannii encodes the production of poly- $\beta-1-6-N$-acetylglucosamine, which is critical for biofilm formation. J. Bacteriol. 2009, 191, 5953-5963. [CrossRef] [PubMed]

8. Mack, D.; Fischer, W.; Krokotsch, A.; Leopold, K.; Hartmann, R.; Egge, H.; Laufs, R. The intercellular adhesin involved in biofilm accumulation of Staphylococcus epidermidis is a linear $\beta-1,6-l i n k e d$ glucosaminoglycan: Purification and structural analysis. J. Bacteriol. 1996, 178, 175-183. [PubMed]

9. Maira-Litran, T.; Kropec, A.; Abeygunawardana, C.; Joyce, J.; Mark, G., 3rd; Goldmann, D.A.; Pier, G.B. Immunochemical properties of the Staphylococcal poly- $\mathrm{N}$-acetylglucosamine surface polysaccharide. Infect. Immun. 2002, 70, 4433-4440. [CrossRef] [PubMed]

10. Wang, X.; Preston, J.F., 3rd; Romeo, T. The pgaABCD locus of Escherichia coli promotes the synthesis of a polysaccharide adhesin required for biofilm formation. J. Bacteriol. 2004, 186, 2724-2734. [CrossRef] [PubMed] 
11. Vuong, C.; Voyich, J.M.; Fischer, E.R.; Braughton, K.R.; Whitney, A.R.; DeLeo, F.R.; Otto, M. Polysaccharide intercellular adhesin (PIA) protects Staphylococcus epidermidis against major components of the human innate immune system. Cell. Microbiol. 2004, 6, 269-275. [CrossRef] [PubMed]

12. Lee, H.W.; Koh, Y.M.; Kim, J.; Lee, J.C.; Lee, Y.C.; Seol, S.Y.; Cho, D.T.; Kim, J. Capacity of multidrug-resistant clinical isolates of Acinetobacter baumannii to form biofilm and adhere to epithelial cell surfaces. Clin. Microbiol. Infect. 2008, 14, 49-54. [CrossRef] [PubMed]

13. Cucarella, C.; Solano, C.; Valle, J.; Amorena, B.; Lasa, I.; Penades, J.R. Bap, a Staphylococcus aureus surface protein involved in biofilm formation. J. Bacteriol. 2001, 183, 2888-2896. [CrossRef] [PubMed]

14. Hinsa, S.M.; Espinosa-Urgel, M.; Ramos, J.L.; O'Toole, G.A. Transition from reversible to irreversible attachment during biofilm formation by Pseudomonas fluorescens WCS365 requires an ABC transporter and a large secreted protein. Mol. Microbiol. 2003, 49, 905-918. [CrossRef] [PubMed]

15. Latasa, C.; Roux, A.; Toledo-Arana, A.; Ghigo, J.M.; Gamazo, C.; Penades, J.R.; Lasa, I. BapA, a large secreted protein required for biofilm formation and host colonization of Salmonella enterica serovar enteritidis. Mol. Microbiol. 2005, 58, 1322-1339. [CrossRef] [PubMed]

16. Brossard, K.A.; Campagnari, A.A. The Acinetobacter baumannii biofilm-associated protein plays a role in adherence to human epithelial cells. Infect. Immun. 2012, 80, 228-233. [CrossRef] [PubMed]

17. Loehfelm, T.W.; Luke, N.R.; Campagnari, A.A. Identification and characterization of an Acinetobacter baumannii biofilm-associated protein. J. Bacteriol. 2008, 190, 1036-1044. [CrossRef] [PubMed]

18. Lebeaux, D.; Ghigo, J.M.; Beloin, C. Biofilm-related infections: Bridging the gap between clinical management and fundamental aspects of recalcitrance toward antibiotics. Microbiol. Mol. Biol. Rev. 2014, 78, 510-543. [CrossRef] [PubMed]

19. Andersson, D.I.; Hughes, D. Microbiological effects of sublethal levels of antibiotics. Nat. Rev. Microbiol. 2014, 12, 465-478. [CrossRef] [PubMed]

20. Penesyan, A.; Gillings, M.; Paulsen, I.T. Antibiotic discovery: Combatting bacterial resistance in cells and in biofilm communities. Molecules 2015, 20, 5286-5298. [CrossRef] [PubMed]

21. Harada, M.; Yamashita, A. Pharmacological studies on the root bark of paeonia moutan. I. Central effects of paeonol. Yakugaku Zasshi 1969, 89, 1205-1211. [PubMed]

22. Piao, X.; Piao, X.L.; Kim, H.Y.; Cho, E.J. Antioxidative activity of geranium (Pelargonium inquinans ait) and its active component, 1,2,3,4,6-Penta-O-galloyl- $\beta$-D-glucopyranose. Phytother. Res. 2008, 22, 534-538. [CrossRef] [PubMed]

23. Lin, M.H.; Chang, F.R.; Hua, M.Y.; Wu, Y.C.; Liu, S.T. Inhibitory effects of 1,2,3,4,6-Penta-Ogalloyl- $\beta$-D-glucopyranose on biofilm formation by Staphylococcus aureus. Antimicrob. Agents Chemother. 2011, 55, 1021-1027. [CrossRef] [PubMed]

24. Pinkston, K.L.; Singh, K.V.; Gao, P.; Wilganowski, N.; Robinson, H.; Ghosh, S.; Azhdarinia, A.; Sevick-Muraca, E.M.; Murray, B.E.; Harvey, B.R. Targeting pili in enterococcal pathogenesis. Infect. Immun. 2014, 82, 1540-1547. [CrossRef] [PubMed]

25. Weng, L.; Zhang, Y.; Yang, Y.; Wang, L. Isolation of the autoinducer-quenching strain that inhibits LasR in Pseudomonas aeruginosa. Int. J. Mol. Sci. 2014, 15, 6328-6342. [CrossRef] [PubMed]

26. Chabane, Y.N.; Mlouka, M.B.; Alexandre, S.; Nicol, M.; Marti, S.; Pestel-Caron, M.; Vila, J.; Jouenne, T.; de, E. Virstatin inhibits biofilm formation and motility of Acinetobacter baumannii. BMC Microbiol. 2014, 14, 62. [CrossRef] [PubMed]

27. Sawadogo, W.R.; Boly, R.; Cerella, C.; Teiten, M.H.; Dicato, M.; Diederich, M. A survey of marine natural compounds and their derivatives with anti-cancer activity reported in 2012. Molecules 2015, 20, 7097-7142. [CrossRef] [PubMed]

28. Rinehart, K.L., Jr.; Gloer, J.B.; Hughes, R.G., Jr.; Renis, H.E.; McGovren, J.P.; Swynenberg, E.B.; Stringfellow, D.A.; Kuentzel, S.L.; Li, L.H. Didemnins: Antiviral and antitumor depsipeptides from a caribbean tunicate. Science 1981, 212, 933-935. [CrossRef] [PubMed]

29. Liaw, C.C.; Chen, P.C.; Shih, C.J.; Tseng, S.P.; Lai, Y.M.; Hsu, C.H.; Dorrestein, P.C.; Yang, Y.L. Vitroprocines, new antibiotics against Acinetobacter baumannii, discovered from marine Vibrio sp. QWI-o6 using mass-spectrometry-based metabolomics approach. Sci. Rep. 2015, 5, 12856. [CrossRef] [PubMed]

30. Wei, W.C.; Sung, P.J.; Duh, C.Y.; Chen, B.W.; Sheu, J.H.; Yang, N.S. Anti-inflammatory activities of natural products isolated from soft corals of Taiwan between 2008 and 2012. Mar. Drugs 2013, 11, 4083-4126. [CrossRef] [PubMed] 
31. Sheu, J.H.; Ahmed, A.F.; Shiue, R.T.; Dai, C.F.; Kuo, Y.H. Scabrolides A-D, four new norditerpenoids isolated from the soft coral Sinularia scabra. J. Nat. Prod. 2002, 65, 1904-1908. [CrossRef] [PubMed]

32. Ahmed, A.F.; Shiue, R.-T.; Wang, G.-H.; Dai, C.-F.; Kuo, Y.-H.; Sheu, J.-H. Five novel norcembranoids from Sinularia leptoclados and S. parva. Tetrahedron 2003, 59, 7337-7344. [CrossRef]

33. Tseng, Y.J.; Ahmed, A.F.; Dai, C.F.; Chiang, M.Y.; Sheu, J.H. Sinulochmodins A-C, three novel terpenoids from the soft coral Sinularia lochmodes. Org. Lett. 2005, 7, 3813-3816. [CrossRef] [PubMed]

34. Takaki, H.; Koganemaru, R.; Iwakawa, Y.; Higuchi, R.; Miyamoto, T. Inhibitory effect of norditerpenes on LPS-induced TNF- $\alpha$ production from the okinawan soft coral, Sinularia sp. Biol. Pharm. Bull. 2003, 26, 380-382. [CrossRef] [PubMed]

35. Bhargava, N.; Sharma, P.; Capalash, N. Quorum sensing in Acinetobacter: An emerging pathogen. Crit. Rev. Microbiol. 2010, 36, 349-360. [CrossRef] [PubMed]

36. Gaddy, J.A.; Actis, L.A. Regulation of Acinetobacter baumannii biofilm formation. Future Microbiol. 2009, 4, 273-278. [CrossRef] [PubMed]

37. Khodaverdian, V.; Pesho, M.; Truitt, B.; Bollinger, L.; Patel, P.; Nithianantham, S.; Yu, G.; Delaney, E.; Jankowsky, E.; Shoham, M. Discovery of antivirulence agents against methicillin-resistant Staphylococcus aureus. Antimicrob. Agents Chemother. 2013, 57, 3645-3652. [CrossRef] [PubMed]

38. Monnappa, A.K.; Dwidar, M.; Seo, J.K.; Hur, J.H.; Mitchell, R.J. Bdellovibrio bacteriovorus inhibits Staphylococcus aureus biofilm formation and invasion into human epithelial cells. Sci. Rep. 2014, 4, 3811. [CrossRef] [PubMed]

39. Peach, K.C.; Cheng, A.T.; Oliver, A.G.; Yildiz, F.H.; Linington, R.G. Discovery and biological characterization of the auromomycin chromophore as an inhibitor of biofilm formation in Vibrio cholerae. Chembiochem 2013, 14, 2209-2215. [CrossRef] [PubMed]

40. Hentzer, M.; Riedel, K.; Rasmussen, T.B.; Heydorn, A.; Andersen, J.B.; Parsek, M.R.; Rice, S.A.; Eberl, L.; Molin, S.; Hoiby, N.; et al. Inhibition of quorum sensing in Pseudomonas aeruginosa biofilm bacteria by a halogenated furanone compound. Microbiology 2002, 148, 87-102. [CrossRef] [PubMed]

41. Rasmussen, T.B.; Manefield, M.; Andersen, J.B.; Eberl, L.; Anthoni, U.; Christophersen, C.; Steinberg, P.; Kjelleberg, S.; Givskov, M. How Delisea pulchra furanones affect quorum sensing and swarming motility in Serratia liquefaciens MG1. Microbiology 2000, 146, 3237-3244. [CrossRef] [PubMed]

42. Ren, D.; Bedzyk, L.A.; Setlow, P.; England, D.F.; Kjelleberg, S.; Thomas, S.M.; Ye, R.W.; Wood, T.K. Differential gene expression to investigate the effect of (5Z)-4-bromo-5-(bromomethylene)-3-butyl-2(5H)-furanone on Bacillus subtilis. Appl. Environ. Microbiol. 2004, 70, 4941-4949. [CrossRef] [PubMed]

43. Liang, C.H.; Wang, G.H.; Chou, T.H.; Wang, S.H.; Lin, R.J.; Chan, L.P.; So, E.C.; Sheu, J.H. 5-epi-sinuleptolide induces cell cycle arrest and apoptosis through tumor necrosis factor/mitochondria-mediated caspase signaling pathway in human skin cancer cells. Biochim. Biophys. Acta 2012, 1820, 1149-1157. [CrossRef] [PubMed]

44. Fey, P.D.; Olson, M.E. Current concepts in biofilm formation of Staphylococcus epidermidis. Future Microbiol. 2010, 5, 917-933. [CrossRef] [PubMed]

45. Niu, C.; Clemmer, K.M.; Bonomo, R.A.; Rather, P.N. Isolation and characterization of an autoinducer synthase from Acinetobacter baumannii. J. Bacteriol. 2008, 190, 3386-3392. [CrossRef] [PubMed]

46. Song, J.Y.; Cheong, H.J.; Noh, J.Y.; Kim, W.J. In vitro comparison of anti-biofilm effects against carbapenem-resistant Acinetobacter baumannii: Imipenem, colistin, tigecycline, rifampicin and combinations. Infect. Chemother. 2015, 47, 27-32. [CrossRef] [PubMed]

47. Tseng, S.P.; Lin, Y.T.; Tsai, J.C.; Hung, W.C.; Chen, H.J.; Chen, P.F.; Hsueh, P.R.; Teng, L.J. Genotypes and phenotypes of Staphylococcus lugdunensis isolates recovered from bacteremia. J. Microbiol. Immunol. Infect. 2015, 48, 397-405. [CrossRef] [PubMed]

48. Peeters, E.; Nelis, H.J.; Coenye, T. In vitro activity of ceftazidime, ciprofloxacin, meropenem, minocycline, tobramycin and trimethoprim/sulfamethoxazole against planktonic and sessile Burkholderia cepacia complex bacteria. J. Antimicrob. Chemother. 2009, 64, 801-809. [CrossRef] [PubMed]

(C) 2016 by the authors; licensee MDPI, Basel, Switzerland. This article is an open access article distributed under the terms and conditions of the Creative Commons Attribution (CC-BY) license (http://creativecommons.org/licenses/by/4.0/). 